\title{
Research on the Generated Path of Electronic Commerce System Based on Innovative High-skilled Technology
}

\author{
Songjie Gong \\ Zhejiang Business Technology Institute, Ningbo 315012, China \\ songjie_gong@163.com
}

Keywords: electronic commerce; system technology; generated path

\begin{abstract}
The researchers of electronic commerce systems who have innovative sense and high-skilled ability are required by not only the modern science and technology revolution, but also the economical and social development of a nation. The paper researches on the generated path of electronic commerce system based on innovative high-skilled technology. At first, it gives electronic commerce system technology of innovative high-skilled. Secondly, it presents the solution of the generated path of innovative high-skilled in electronic commerce system. Then, the steps of the generated path are given. Lastly, the paper analyzes some improvements needed to be done and points out the future researching direction.
\end{abstract}

\section{Introduction}

The trading business of electronic commerce on the traditional has brought revolutionary changes to requirements, "product centric" to "customer oriented", "take the customer as the center" of the new business model changes, requirements of e-commerce site by customer group division products, for services around the customer, provide the needed items for customers therefore, to provide personalized service to each customer become necessary. At first, this paper gives electronic commerce system technology of innovative high-skilled. Secondly, it presents the solution of the generated path of innovative high-skilled in electronic commerce system. Then, the steps of the generated path are given. Lastly, the paper analyzes some improvements needed to be done and points out the future researching direction.

\section{Electronic commerce system technology of innovative high-skilled}

\section{According to the frequent item sets to generate Recommendation sets}

Focus on the frequent item, each candidate projects recommended value according to the right is the association rules of the project to determine the credibility, if the confidence of the association rule is greater than a given threshold value, the project can add the recommended set. The specific algorithm is as follows: Input with a maximum capacity of dynamic user session window w s; Webpage topological map for the current web site; support threshold value $\delta$, trust threshold value $\alpha$.

Recommend $=\Phi$;

For $\mathrm{I}=\mathrm{z}+1$, w I, do

If $\operatorname{support}(\mathrm{I}) \geq \delta$ then

$\mathrm{c}=$ confidence $(\mathrm{w} \cdot \mathrm{u} 0)$;

If $\mathrm{c} \geq \alpha$ then

u.rec score $=\mathrm{c} \operatorname{ldf}(\mathrm{u}, \mathrm{w})$;

Recommend=Recommend $\mathrm{U}<\mathrm{u}=$

End if

End if

End for 


\section{System evaluation}

The on-line assessment is the evaluation of the recommendation system users online survey. Have done a comparative evaluation of recommender systems make friends and make recommendations, the experimental results show that the recommendation of friends more often than recommended better recommendation system, recommendation system is given and the recommendation than the recommendation of friends updates, and identified several key factors recommended design. Offline evaluation with a known data set to evaluate the recommendation system of.

Mean Absolute Error, MAE

$$
M A E=\frac{\sum_{i=1}^{N}\left|p_{i}-q_{i}\right|}{N}
$$

Top - $\mathrm{N}$ to measure the recommendation quality generally uses the field evaluation system of information retrieval standard, with precision and recall measure:

Table 1: precision and recall

\begin{tabular}{|l|l|l|}
\hline $\begin{array}{l}\text { The actual value / predictive } \\
\text { value }\end{array}$ & negative number of $\mathrm{K}$ & set number \\
\hline Negative number & a & b \\
\hline K fixed number & c & d \\
\hline
\end{tabular}

$$
\begin{aligned}
& \text { precision }=\frac{\mathrm{d}}{\mathrm{b}+\mathrm{d}} \\
& \text { precision }=\frac{\mathrm{d}}{\mathrm{c}+\mathrm{d}} \\
& \mathrm{F} \text { - measure : } \\
& F-\text { mrasure }=\frac{2 \text { precision } \bullet \text { recall }}{\text { precision }+ \text { recall }}=\frac{2}{1 / \text { precision }+1 / \text { recall }}
\end{aligned}
$$

E- measurer:

$$
E-\text { measure }=\frac{1}{\alpha(1 / \text { precision })+(1-\alpha)(1 / \text { recall })}
$$

\section{Electronic commerce collaborative filtering}

The cosine similarity measure, user rating as a vector of dimension n space, if the user of the item did not score, will the user to the score is set to 0 , the similarity between users through the cosine angle between two vectors measure. Set user I and user $\mathrm{J}$ in the $\mathrm{n}$ dimension space of the scores were expressed as the similarity between sim vector users I and J (I, J) for:

$$
\operatorname{sim}(i, j)=\cos (\bar{i}, \bar{j})=\frac{\bar{i}, \bar{j}}{\|\bar{i}\|\|\bar{j}\|}
$$

Modified cosine correlation has fully considered the score scale problem of different users, the project's score by subtracting the users to realize its advantages. A combination score users I and $\mathrm{j}$, between the user I and user similarity of $\mathrm{J} \operatorname{sim}(\mathrm{I}, \mathrm{J})$ for:

$$
\operatorname{sim}(i, j)=\frac{\sum_{c \in I_{i, j}}\left(R_{i c}-\bar{R}_{i}\right)\left(R_{j c}-\bar{R}_{j}\right)}{\sqrt{\sum_{c \in I_{i, j}}\left(R_{i c}-\bar{R}_{i}\right)^{2}} \sqrt{\sum_{c \in I_{j, c}}\left(R_{j c}-\bar{R}_{j}\right)^{2}}}
$$

Correlation similarity measure and said the Pearson correlation coefficient, a user I and user $\mathrm{J}$ common score. A collection of items with Ii, j=I1 I2 says, the user I and user J similarity sim (I, J) for:

$$
\operatorname{sim}(i, j)=\frac{\sum_{c \in I_{i, j}}\left(R_{i, c}-\bar{R}_{i}\right)\left(R_{j, c}-\bar{R}_{j}\right)}{\sqrt{\sum_{c \in I_{i, j}}\left(R_{i, c}-\bar{R}_{i}\right)^{2}} \sqrt{\sum_{c \in I_{j, c}}\left(R_{j, c}-\bar{R}_{j}\right)^{2}}}
$$

The nearest neighbor set user $\mathrm{U}$ set by $\mathrm{Nu}$, the user $\mathrm{u}$ to the project I score in predicting $\mathrm{Pu}, \mathrm{I}$ can get to the nearest neighbors of an item in the Nu score by user $\mathrm{u}$, calculated as follows: 


$$
P_{u, i}=\bar{R}_{u}+\frac{\sum_{n \in N N_{u}} \operatorname{sim}(u, n)\left(R_{n, i}-\bar{R}_{n}\right)}{\sum_{n \in N N_{u}}|(\operatorname{sim}(u, n))|}
$$

\section{Generated path of innovative high-skilled in electronic commerce}

Based on optimization theory, the optimization path generation of high skill talent is to explore innovative. Comparison of the generated path, path generation of college enterprise cooperation and the advantages and disadvantages of the generated path of school and enterprise, is by using system theory and mathematical method, considering the relationship between the government, enterprises, universities, and ultimately the formation of the optimization path of high skilled personnel training innovation, as shown in Figure 1.

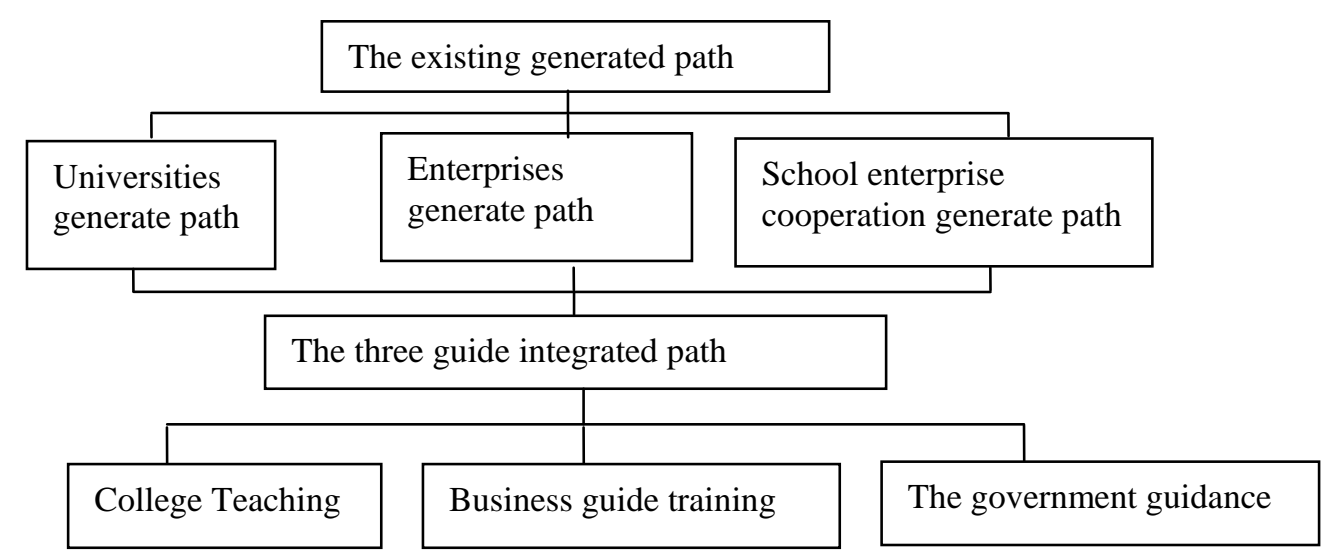

Figure 1 The innovative highly skilled generated path of electronic commerce

First of all, the growth mechanism of the extensive investigation of cultivating innovative talents with high skill in domestic universities, colleges and universities leading investigation of high skilled talents training innovation, and carried out and their teaching administrators and teachers are widely deep discussion and research. Secondly, make social investigation to the industry, enterprise. According to the different courses, the representative of the enterprise, the company talent demand information research, understand the enterprise talent requirements of knowledge, ability, technical ability, quality and ability, competence, and has grasped the first material. At the same time, tracking survey of graduates' employment of graduates, understanding and working condition, the collection of the employing units to the school teaching feedback, provide the basis for the growth mechanism of high skilled talents of our exploration and Research on innovative culture. Once again, consult the experts. Through consulting, academic reports and other forms, consult the domestic famous expert. Invited experts to give lectures on the school, and in our faculty and high learning, to carry out a large-scale discussion of concept transformation of education thought and employees, lay the ideological foundation for the development of innovative high skill education. In addition, also uses the seminars and individual consulting method, extensively solicit opinions and suggestions on the innovation of high skills education of each industry experts committee.

\section{Steps of the research}

Choose computer class representative of the class of objects any implementation team leader, the person in charge of each course, a number of teachers directly involved in the study of the growth mechanism of innovative high-skilled personnel training. Theoretical research and practical exploration of the subject generally need to go through the following process, as shown in Figure 2. 


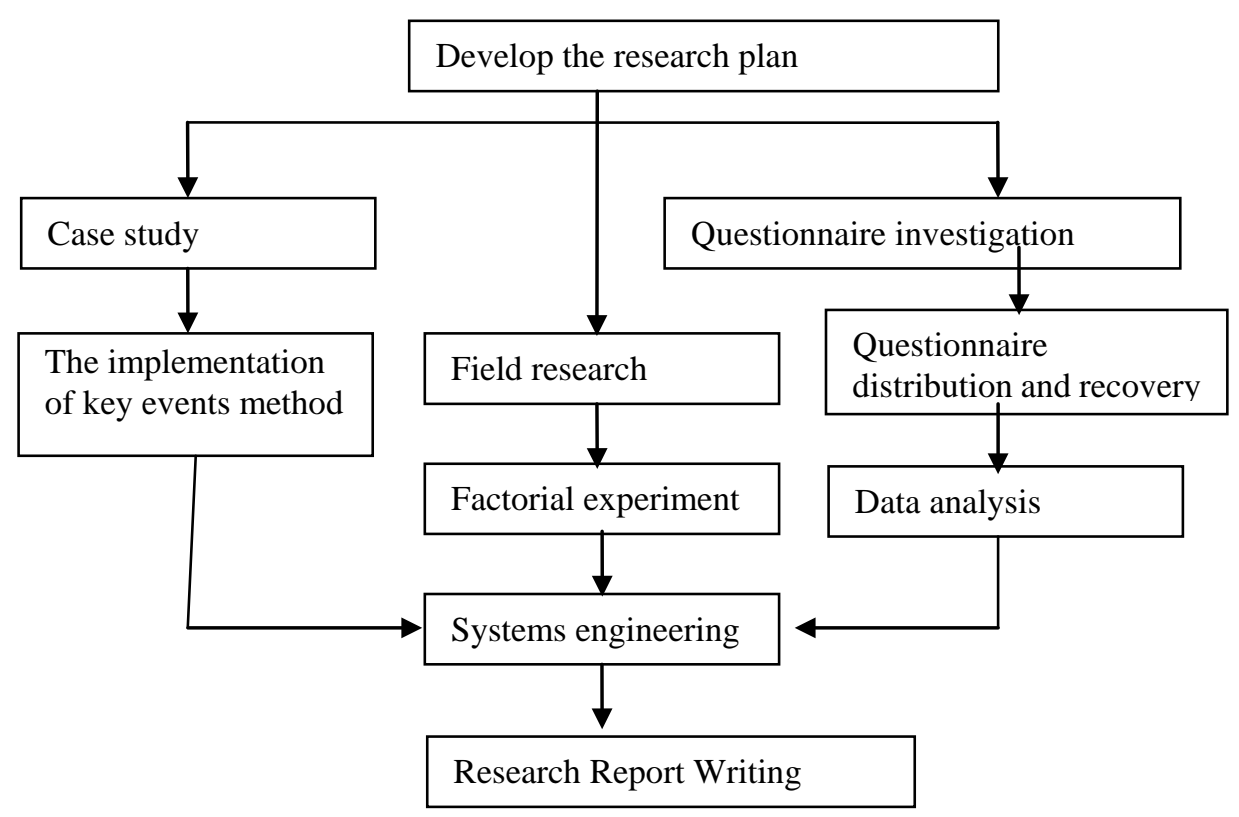

Figure 2 The steps of the research

\section{Summary}

This paper researches on the generated path of electronic commerce system based on innovative high-skilled technology. At first, the paper gives electronic commerce system technology of innovative high-skilled. Secondly, it presents the solution of the generated path of innovative high-skilled in electronic commerce system. Then, the steps of the generated path are given. Lastly, the paper analyzes some improvements needed to be done and points out the future researching direction.

\section{Acknowledgment}

A Project Supported by Scientific Research Fund of Zhejiang Province Human Resources and Social Security Bureau (Grant No. R2014R022).

\section{References}

[1] Songjie Gong, Research on the Growth Mechanism of High-Skilled System in Computer Science and Technology, Applied Mechanics and Materials, Vol. 513, pp: 2748-2751, 2014.

[2] Hughes, N.L. Changing faces: Adaptation of highly skilled Chinese workers to a high-tech multinational corporation[J]. Journal of Applied Behavioral Science. 2009, 45(2):212-238

[3] Reetz, L.: Handlung, Wissen und Kompetenz als strukturbildende Merkmal von Lemfeldern, In Bader, R./ Sloane, P.F.E. (Hrsg): Lernen in Lernfeld, Eusl-Verlag, Markt Schwaben 2000, S.141-150.

[4] Billett, S. Learning in the workplace: strategies for.effective practice. Singapore: CMO Image Printing Enterprise.2001 P. 34.

[5] Shintoyo , N. Worker-financed versus firm-sponsored training: How are skilled workers supplied to the economy[J]. Economica 2010, 77 (305): 110-127

[6] Johnson D. W, Johnson. R. J \& E J Hulubec. Circles of Learning: cooperation in the classroom [M]. Edina, Minn: Interaction Book Company, 1990

[7] Deirdre Cook, John Ralston. Building the cognitive bridge: children, information technology and thinking [M]. Education and information technologies, 2005 